\title{
ESTUDO DA EXTRAÇÃO DE CORANTE NATURAL QUE CONFERE PROTEÇÃO ULTRAVIOLETA EM FIBRAS NATURAIS
}

\author{
A. C. LUCARINI ${ }^{1, *}$, A. S. F. Z. TABU ${ }^{1}$, F. F. R. SILVA ${ }^{1}$, G. A. MORAES ${ }^{1}$, G. I. PIAZON ${ }^{1}$, \\ M. P. ZURAWSKI ${ }^{1}$ \\ ${ }^{1}$ Centro Universitário FEI, Departamento de Engenharia Química \\ *E-mail: lucarini@fei.edu.br
}

\begin{abstract}
RESUMO: Neste trabalho estudaram-se parâmetros do processo de extração de bixina e norbixina a partir do urucum e a proteção ultravioleta conferida pelo corante à uma fibra natural. Avaliaram-se diferentes solventes de extração: acetona, acetato de etila, $\mathrm{KOH}$ em solução e etanol, bem como as misturas entre eles. Analisaram-se os efeitos de: temperatura (30 a 60oC); tamanho do sólido (semente intacta e moída); tempo de extração e razão mássica sólido/solvente nas proporções de 0,125, 0,25 e 0,42. Com os resultados obtidos verificou-se uma melhor extração utilizando-se a mistura etanol:acetona $50 \%$ (v/v), temperatura de $55^{\circ} \mathrm{C}$ e tamanho da partícula de $100 \mathrm{MESH}$. A partir dos parâmetros adotados foi possível concluir que houve a saturação do solvente em 20 minutos de extração e com isso, concluiu-se que o sólido pode ser aproveitado para mais de um ciclo de extração. Verificou-se uma proteção ultravioleta conferida pelo corante aplicado no algodão alvejado de $89 \%$ da radiação ultravioleta absorvida.
\end{abstract}

PALAVRAS-CHAVE: Corantes Naturais; Extração; Proteção UV; Bixina; Norbixina.

\section{INTRODUÇÃO}

Atualmente uma das principais preocupações da população mundial gira em torno da sustentabilidade e dos resíduos produzidos e descartados no meio ambiente. Com isso, são extremamente importantes as iniciativas tomadas a fim de melhorar a situação ambiental, e a indústria química vem buscando alternativas frente à necessidade de apresentar novas tecnologias menos nocivas à natureza. Há 4000 anos, foram descobertos registros de alguns tipos de corantes naturais usados pelo homem. Porém, com a descoberta dos corantes sintéticos pelo químico Willian Perkin, em 1856, houve uma diminuição no consumo de corantes naturais em tecidos, chegando quase à extinção de sua utilização (MIRJALILI et al., 2011).

Existem diversas aplicações para corantes e pigmentos, sendo os cosméticos e tingimento de fibras têxteis as de maior importância. Devido à preocupação com o consumidor final, os fabricantes têm investido em pesquisas para aperfeiçoar a produção de 
corantes naturais a fim de diminuir o risco do uso de substâncias cancerígenas e tóxicas aos seres humanos (MENTER; HATCH, 2003). Tal investigação possibilita a descoberta de diversas formas de extração e utilização sustentável de recursos naturais para a obtenção de corantes e pigmentos, verificando a viabilidade de sua aplicação frente aos corantes sintéticos já existentes (VIANA, 2012).

Corantes são substâncias de cor intensa que conferem a um material uma determinada coloração através de técnicas como adsorção, retenção mecânica ou ligações químicas, que dependem da afinidade com a matriz (ABIQUIM, 2012). Diferem-se de pigmentos por não interferirem na opacidade do material, apenas em sua coloração, mantendo a transparência do mesmo praticamente inalterada. Além de poderem ser solúveis no material em que se deseja o tingimento como, por exemplo, em laticínios (MENDA, 2011).

O uso de corantes naturais data da pré-história nas pinturas rupestres, onde eram usados para diferentes tipos de decoração e para dar uma apresentação atrativa a vários produtos, até mesmo na pintura corporal. Na história do Brasil, existe uma grande influência do pau-brasil, o qual era muito utilizado devido à sua cor vermelha, e foi exportado para a Europa desde a colonização. Os corantes naturais são substâncias derivadas de animais, vegetais ou minerais (DIAS, 2010). O uso dos corantes naturais decresceu com o aparecimento dos corantes sintéticos em 1856, os quais possuíam muitas vantagens, pois apresentavam maior estabilidade, uma vez que os naturais sofrem alteração quando expostos a variações de temperaturas e $\mathrm{pH}$ e degradação com a luz. No entanto, apesar do corante natural poder sofrer mudança de coloração, são de grande importância por não causarem danos à saúde e terem uma natureza sustentável (COSTA, 2010). A estabilidade do corante natural está ligada ao tamanho da molécula, ao tamanho dos agregados absorvidos na superfície da fibra e ao tipo de fixador escolhido. Também dependem da intensidade das radiações que incidem na molécula (raios gama e ultravioleta), pois ocorre a formação de radicais livres que atuam nas insaturações da molécula, responsáveis pela coloração do corante, podendo rompê-la até desaparecimento da cor ou desbotamento (COSTA, 2010).

No momento atual, o uso destes corantes tem um grande interesse econômico nas indústrias alimentícia, têxtil e de cosméticos, porém ainda são necessários estudos para obtenção de produtos que além de elevada pureza tenham uma boa qualidade de cor e estabilidade (DIAS, 2010). As indústrias de corantes realizam estudo e pesquisas de métodos que melhorem a estabilidade destes corantes, como microencapsulação, complexação e adsorção, para que desta maneira o uso se torne menos restrito (DIAS, 2010).

A semente do urucum (Bixa orellana L.) é derivada de uma planta que ocorre em regiões tropicais e devido à sua ampla distribuição geográfica possui mais de 50 nomes diferentes. A planta do urucum pertence à família bixaceae e possui uma grande variedade de coloração. No Brasil, sua expansão ocorreu devido à facilidade de adaptação de sua cultura em várias regiões do país, principalmente Nordeste, Norte e Sudeste. Neste país, também existem quatro variedades mais comuns, que possuem cascas avermelhadas, verdes, brancas e púrpuras (VERÍSSIMO, 2003). O urucum destaca sua importância econômica sendo uma das principais e maiores fontes de corantes vermelhos. A planta do urucum tradicionalmente era usada pelos índios e peruanos com a finalidade de proteger a pele contra os raios ultravioletas e contra picadas de insetos (SOUZA, 2011). A coloração dos extratos do 
urucum está relacionada aos percentuais de bixina e norbixina, que são carotenoides. A bixina leva a uma coloração vermelha escura enquanto a norbixina a uma coloração amarelada. Este grupo encontrado em vegetais é classificado como carotenos ou xantofilas. Os carotenos são hidrocarbonetos poliênicos com variados graus de insaturação, e as xantofilas são sintetizadas a partir dos carotenos, por meio de reações de hidroxilação e epoxidação (COSTA, 2010). A bixina foi isolada primeiramente em 1875, e sua estrutura completa e estereoquímica foram estabelecidas em 1961, representadas na Figura 1 (DIAS, 2010).<smiles>CC(/C=C/C=C/C(=O)O)=C\C=C\C=C(C)\C=C\C=C(C)\C=C\C(=O)O</smiles><smiles>CC(=O)/C=C/C(C)=C\C=C\C(C)=C\C=C\C=C\C=C\C=C\C=C\C(=O)O</smiles>

Figura 1 - Representação da estrutura química da bixina e da norbixina (DIAS, 2010).

A extração dos corantes do urucum normalmente é feita a partir da camada externa das sementes, onde se encontra mais de $80 \%$ dos carotenóides totais presentes, inclusive a bixina e a norbixina (SILVA, 2007). A norbixina possui poder de coloração parecido com o da bixina e é o corante natural mais utilizado no Brasil representando cerca de $80 \%$ do consumo, principalmente em indústrias alimentícias. Comparado com os outros corantes naturais, possui maior estabilidade e coloração mais atrativa e é uma das principais matérias-primas, da indústria de laticínios (SILVA, 2007). A cis-bixina é o corante mais importante do urucum, é um éster monometílico da cis-norbixina que é um ácido carboxílico e possui nove ligações olefínicas conjugadas com a configuração cis. Esta configuração é instável e em solução, sob aquecimento, pode ser parcialmente transformada na configuração trans, mais estável, como mostra a Figura 2 (SILVA, 2007).

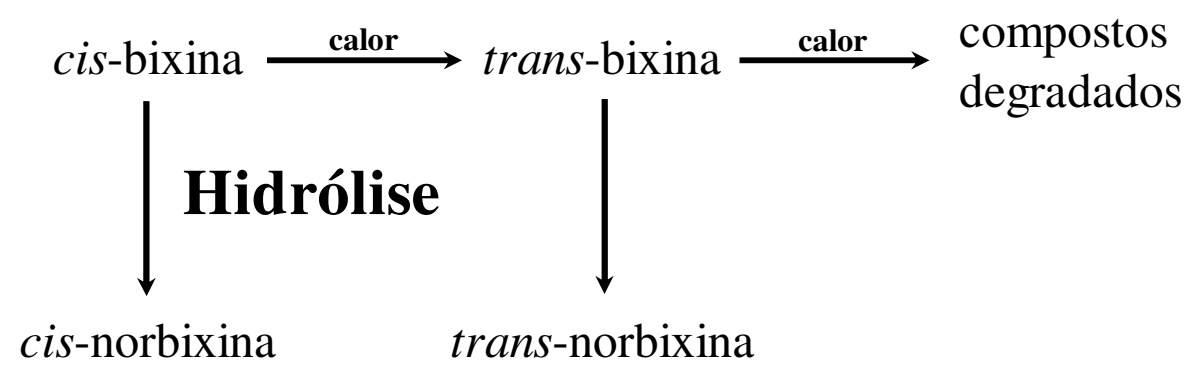

Figura 2 - Inter-relação entre os diferentes corantes do urucum (HENRY, 1996). 
Os métodos de extração a partir da semente podem envolver duas possibilidades: a produção somente de bixina por extração com solventes orgânicos ou, através da hidrólise em meio alcalino, a extração de norbixina (SILVA, 2007). Em escala industrial, os três métodos mais comumente utilizados para extrair o corante das sementes são: (1) a extração aquosa alcalina, que resulta na conversão do carotenoide bixina de uma forma de éster monometílico lipossolúvel (possui afinidade com óleos e gorduras) a sal de norbixina hidrossolúvel (possui afinidade com água); (2) a extração em óleo, que resulta na remoção da bixina das sementes além de pequenas quantidades de outros materiais coloridos lipossolúveis, e; (3) a extração com solventes orgânicos, que resulta na forma mais pura do corante bixina (PRENTICE HERNANDEZ et al., 1992). Todos os métodos utilizados para extração de bixina e norbixina estão baseados na operação unitária de extração sólido-líquido ou lixiviação. A lixiviação é um método que consiste na transferência de um soluto presente em um sólido para um solvente, que é a fase líquida (GEANKOPLIS, 2003).

Contudo, por corantes naturais serem substâncias sensíveis à luz e ao calor, as técnicas de extração dos corantes do urucum devem levar em consideração a possível degradação do corante com as condições operacionais adotadas. De acordo com Lancaster e Lawrence (1996), a temperatura e o tempo de aquecimento do processo são responsáveis pelo balanço da coloração vermelho/amarelo obtida no corante final. No caso da extração de corantes naturais de sólidos, como é o caso dos corantes extraídos do urucum, um inconveniente deste método é a grande concentração de impurezas provenientes da semente que são arrastadas juntamente com o produto de interesse (SILVA, 2007). Para tal, é importante estudar o tamanho e distribuição dos grãos dos sólidos particulados, parâmetro que influencia diretamente na eficiência da extração (GEANKOPLIS, 2003).

Uma das características dos corantes é a sua aplicação como protetor em relação à radiação UV evitando degradação de materiais devido à exposição contínua ao sol e o nível da proteção varia conforme a concentração do mesmo. Porém, a maioria das pesquisas está relacionada ao uso de corantes sintéticos, pois os corantes naturais exigem desenvolvimento na sua fixação à fibra, principal fator limitante ao seu uso, além da pouca variedade de colorações (VIANA, 2012).

A importância da foto proteção com o aumento do aquecimento global é incontestável, fato comprovado pelo crescente número de casos de câncer de pele devido ao efeito nocivo da radiação ultravioleta (PEREIRA, 2016). A proteção contra os danos causados pela exposição solar geralmente é feita através do uso de protetores solares e vestimentas adequadas que impedem a passagem da radiação UV (MENTER; HATCH, 2003). Roupas, chapéus e óculos são comumente utilizados para prevenir os males causados pela radiação, observa-se ao longo dos anos uma evolução notável de produtos com propriedades foto protetoras, como é o caso de uniformes para atletas cuja exposição solar é grande. Para essas vestimentas é conferido um fator de proteção que é chamado de FPU (Fator de Proteção Ultravioleta). Este relaciona o tempo de exposição segura ao sol em relação ao tempo de exposição sem proteção (BALOGH et al., 2011). O uso de corantes ou pigmentos que conferem proteção ultravioleta às fibras têxteis sejam elas naturais ou sintéticas, é útil para a produção de tecidos que auxiliarão na proteção ultravioleta de pessoas que se expõem por longos períodos à radiação solar, como, por exemplo, trabalhadores da construção civil e limpeza urbana (SILVA, 1997). 
O objetivo principal deste trabalho foi estudar a extração de um corante natural que apresentasse proteção ultravioleta em tecidos. Além da escolha inicial da matéria-prima de origem vegetal, levando-se em conta disponibilidade da mesma e suas características de proteção UV, o objetivo deste trabalho foi o estudo de alguns parâmetros para definição de um processo de extração sólido-líquido eficaz, tais como: tipo de solvente, temperatura, tamanho da partícula, e a influência do tempo de extração e a razão matéria-prima/solvente para extração em processo descontínuo. Após a extração, também se realizou o tingimento e a determinação da proteção ultravioleta conferida à fibra de algodão pelo corante extraído.

\section{MATERIAL E MÉTODOS}

\subsection{Estudo da Extração Sólido-Líquido do Corante Natural do Urucum}

No estudo da escolha do solvente de extração, da temperatura e do tamanho de partícula, os ensaios de extração foram realizados de forma descontínua, da seguinte forma: $15 \mathrm{~g}$ de sementes de urucum intactas foram misturadas em um erlenmeyer com $150 \mathrm{~mL}$ de solução de extração. As misturas foram colocadas em agitador orbital a $150 \mathrm{rpm}$ por 2 horas, a $30^{\circ} \mathrm{C}$. Nos ensaios da influência da temperatura na extração foram testadas as temperaturas de 45,55 e $60^{\circ} \mathrm{C}$. Após este período foram filtradas e centrifugadas a $3000 \mathrm{rpm}$ por 10 minutos, a fim de separar a fase líquida da fase sólida. A fase líquida seguiu para análise do teor de bixina/norbixina e sólidos solúveis totais (SST).

Para o estudo da influência do tamanho da partícula na extração, foram utilizadas sementes de urucum moídas em um triturador doméstico por cerca de 10 minutos. Após a moagem dos grãos, o produto foi introduzido a um conjunto de peneiras previamente pesadas, da série Tyler com ASTM de 30, 50 e 100 MESH, e colocadas em um agitador com frequência de $15 \mathrm{rpm}$ por 25 minutos para a separação das frações de tamanhos diferentes.

No estudo da influência do tempo de extração e da proporção de sólido/solvente, variou-se a razão mássica de sólido/solvente em 0,$125 ; 0,25$ e 0,42 ( $\mathrm{g}$ urucum/ $\mathrm{g}$ solvente). Utilizou-se um banho termostático a $55^{\circ} \mathrm{C}$, tamanho de semente moída de $100 \mathrm{MESH}$ e solução de extração acetona:etanol $50 \%(\mathrm{v} / \mathrm{v})$. Esta mistura foi colocada sob agitação mecânica a $150 \mathrm{rpm}$ e foram retiradas alíquotas de $5 \mathrm{~mL}$ em diferentes tempos para a análise do teor de bixina/norbixina.

\subsection{Determinações Analíticas}

Para a determinação do teor de sólidos solúveis totais - SST (g/L), $30 \mathrm{~mL}$ de cada extrato obtido, após centrifugação, foi colocado em placas de Petri previamente higienizadas e taradas, e levadas à estufa a $65^{\circ} \mathrm{C}$ até obtenção de massa constante, o que foi conferido por diversas pesagens consecutivas.

Para a determinação da concentração de bixina e norbixina foi utilizado uma adaptação do método espectrofotométrico descrito por Bareth et al. (2002). Para análise do teor de bixina e norbixina foram pesadas com precisão massas do extrato obtido, em um balão volumétrico de $25 \mathrm{~mL}$, com adição de clorofórmio (para bixina) ou uma solução 2,5 \% (m/m) de $\mathrm{KOH}$ (para norbixina), até completar o volume do balão. Em seguida, as preparações foram agitadas para homogeneização da solução. A faixa ideal para a leitura das absorvâncias 
esta compreendida no intervalo entre 0,3 e 0,8 e o comprimento de onda específico para cada solução é de $498 \mathrm{~nm}$ para a bixina e $482 \mathrm{~nm}$ para a norbixina, e caso a absorvância lida estivesse muito distante das indicadas a preparação deveria ser alterada, utilizando-se balões de 50, 100 ou 250mL, podendo-se também alterar a massa de extrato nos balões caso fosse necessário. Conhecidas as absorvâncias, determinou-se a concentração das mesmas pela Equação 1, obtida do método utilizado como referência (BARETH et al., 2002).

$$
\beta=\frac{A_{\lambda} \times 1000}{E_{1 c m}^{1 \%}}
$$

Onde: $E_{1 \mathrm{~cm}}^{1 \%}$ corresponde ao coeficiente de extinção de cada substância (2870 tanto para bixina quanto para norbixina nos comprimentos de onda utilizados), $\beta$ é a concentração de bixina ou norbixina na solução [mg/L] e $A_{\lambda}$ é o valor da absorvância lida a 498nm para bixina e $482 \mathrm{~nm}$ para norbixina.

\subsection{Aplicação do Corante Natural e Caracterização da Proteção UV}

Foi adicionado 4,5 g do tecido de algodão previamente alvejado a um banho de tingimento. Este ficou cerca de 30 minutos no banho a $120^{\circ} \mathrm{C}$ a $30 \mathrm{rpm}$ em contato com $50 \%$ da massa do tecido de corante. Ao término do tingimento, o tecido passou por uma centrífuga por 5 minutos, em seguida, o tecido foi para um forno onde ficou a $120^{\circ} \mathrm{C}$ durante um período de 3 minutos. O tecido seco foi levado a uma câmara com lâmpada ultravioleta TL84 com comprimentos de onda de 280 - $400 \mathrm{~nm}$ e foi medida a radiação que passava sobre duas amostras de tecido com o auxílio de um sensor ultravioleta, contra um padrão de tecido alvejado. Foram realizadas três medições de radiação: uma somente da radiação emitida pela lâmpada, outra da que atravessa o algodão sem tingimento, e outra da que atravessa o algodão tingido. A radiação foi obtida em $\left(\mu \mathrm{W} / \mathrm{cm}^{2}\right)$ e transformada para FPU pela relação descrita na Tabela 1 com o resultado de UVR obtido na Equação 2.

$$
U V R=\frac{(R L-R T)}{R L} \times 100
$$

Onde: RL é a radiação emitida pela lâmpada (em $\left.\mu \mathrm{W} / \mathrm{cm}^{2}\right)$, RT a radiação através do tecido (também em $\mu \mathrm{W} / \mathrm{cm}^{2}$ ) e UVR é a \% de radiação ultravioleta retida no tecido.

Tabela 1 - Classificação da Proteção UV conferida por tecidos (INMETRO, 2016).

\begin{tabular}{ccc}
\hline FPU & Categoria & UVR $(\mathbf{\%})$ \\
\hline $15-24$ & Boa & 93,3 a 95,9 \\
$25-39$ & Muito Boa & 96 a 97,4 \\
$40-50+$ & Excelente & Mais de 97,5 \\
\hline
\end{tabular}

\section{RESULTADOS E DISCUSSÃO}

A primeira etapa deste projeto envolveu a escolha da matéria-prima vegetal para a extração do corante natural. Foi realizada uma pesquisa bibliográfica de diferentes fontes de carotenoides, como mostra a Tabela 2. De acordo com a Tabela 2, para este trabalho, foi 
escolhido o urucum como matéria-prima vegetal, devido ao seu grande poder tintorial, alta disponibilidade no Brasil durante todo o ano, facilidade de armazenamento das sementes, estabilidade de coloração e elevada proteção ultravioleta (UV).

Tabela 2 - Dados obtidos da literatura para a escolha da matéria-prima.

\begin{tabular}{ccccc}
\hline $\begin{array}{c}\text { Matéria- } \\
\text { Prima }\end{array}$ & $\begin{array}{c}\text { Proteção } \\
\text { UV }\end{array}$ & $\begin{array}{c}\text { Disponibilidade } \\
\text { durante o ano }\end{array}$ & $\begin{array}{c}\text { Estabilidade do } \\
\text { componente }\end{array}$ & Fonte \\
\hline Abóbora & Sim & Sim & - & (Menda, 2011) \\
Cenoura & Sim & Sim & - & (Schiozer; Barata, 2007) \\
Jabuticaba & Sim & - & Sim & (Mathias, 2015) \\
Folhas & Sim & Sim & - & (Heaton; Marangoni, 1996) \\
Verdes & Sim & Sim & Sim & (Souza, 2011) \\
Urucum & & & &
\end{tabular}

\subsection{Estudo da Extração Sólido-Líquido do Corante Natural do Urucum}

Foram estudadas algumas das variáveis que afetam o processo de lixiviação: o tipo de solvente, a granulometria do sólido, a temperatura, o tempo de extração e proporção sólido/solvente na extração.

Estudo do solvente de extração: A escolha do solvente de extração foi baseada na análise dos resultados do teor de bixina e norbixina e do teor de sólidos solúveis totais obtidos nos extratos após extração. Para isso definiu-se uma grandeza chamada "razão mássica" que foi calculada pela razão da massa de corante extraído (mg) e da massa de sólidos solúveis totais (g) no extrato. A Tabela 3 apresenta os dados obtidos para cada solvente de extração de teor de bixina/norbixina e sólidos solúveis totais.

Tabela 3 - Dados obtidos de teores de bixina e norbixina e sólidos solúveis totais para diferentes solventes de extração.

\begin{tabular}{cccc}
\hline Solventes & $\begin{array}{c}\text { Bixina } \\
(\mathbf{m g} / \mathbf{L})\end{array}$ & $\begin{array}{c}\text { Norbixina } \\
(\mathbf{m g} / \mathbf{L})\end{array}$ & $\begin{array}{c}\text { SST } \\
(\mathbf{g} / \mathbf{L})\end{array}$ \\
\hline Etanol Anidro & $1,18 \pm 0,03$ & $2,26 \pm 0,10$ & 2,40 \\
Etanol hidratado 95\% (v/v) & $0,89 \pm 0,06$ & $1,83 \pm 0,30$ & 2,30 \\
Acetona Pura & $2,48 \pm 0,27$ & $1,69 \pm 0,21$ & 3,75 \\
Acetona:Água 50\%(v/v) & $0,98 \pm 0,27$ & $0,35 \pm 0,03$ & 1,57 \\
Acetona:Etanol 50\%(v/v) & $2,17 \pm 0,24$ & $1,55 \pm 0,11$ & 3,60 \\
Acetato de Etila & $1,48 \pm 0,17$ & $2,09 \pm 0,03$ & 2,40 \\
Acetato de Etila:Acetona 50\%(v/v) & $2,32 \pm 0,30$ & $1,42 \pm 0,18$ & 3,34 \\
Acetato de Etila:Etanol 50\%(v/v) & $2,18 \pm 0,27$ & $1,25 \pm 0,20$ & 2,87 \\
KOH 1M & $0,51 \pm 0,06$ & $2,01 \pm 0,03$ & 85,12 \\
KOH 1 M: Acetona 50\%(v/v) & $1,71 \pm 0,13$ & $1,78 \pm 0,05$ & 37,82 \\
KOH 1 M: Etanol 50\%(v/v) & $1,49 \pm 0,17$ & $1,45 \pm 0,04$ & 33,24 \\
KOH 1 M: Acetato de Etila 50\%(v/v) & $1,01 \pm 0,91$ & $1,24 \pm 0,01$ & 88,87 \\
\hline
\end{tabular}

A escolha do solvente se dá pela afinidade deste com o soluto desejado e deve ser preferivelmente de baixa viscosidade para melhor escoamento. No caso dos solventes alcalinos a extração de bixina é relativamente baixa devido à saponificação de bixina em 
norbixina, resultando nas melhores capturas totais de norbixina. Porém, em meio alcalino houve a extração de outros sólidos solúveis em grande quantidade o que resultou num extrato muito impuro o que foi revelado pelos baixos valores de razão mássica. Analisando-se a extração conjunta de bixina e norbixina, o solvente de extração escolhido para a continuidade do trabalho foi a solução de acetona:etanol 50\% (v/v), como demonstrado na Figura 3. Este solvente pode ser facilmente eliminado do extrato e reciclado para reuso no processo, além de não ser tóxico caso permaneça algum residual de solvente no corante. O solvente acetato de etila apresentou o inconveniente de extrair junto com o corante a fração lipídica das sementes, formando um sistema bifásico.

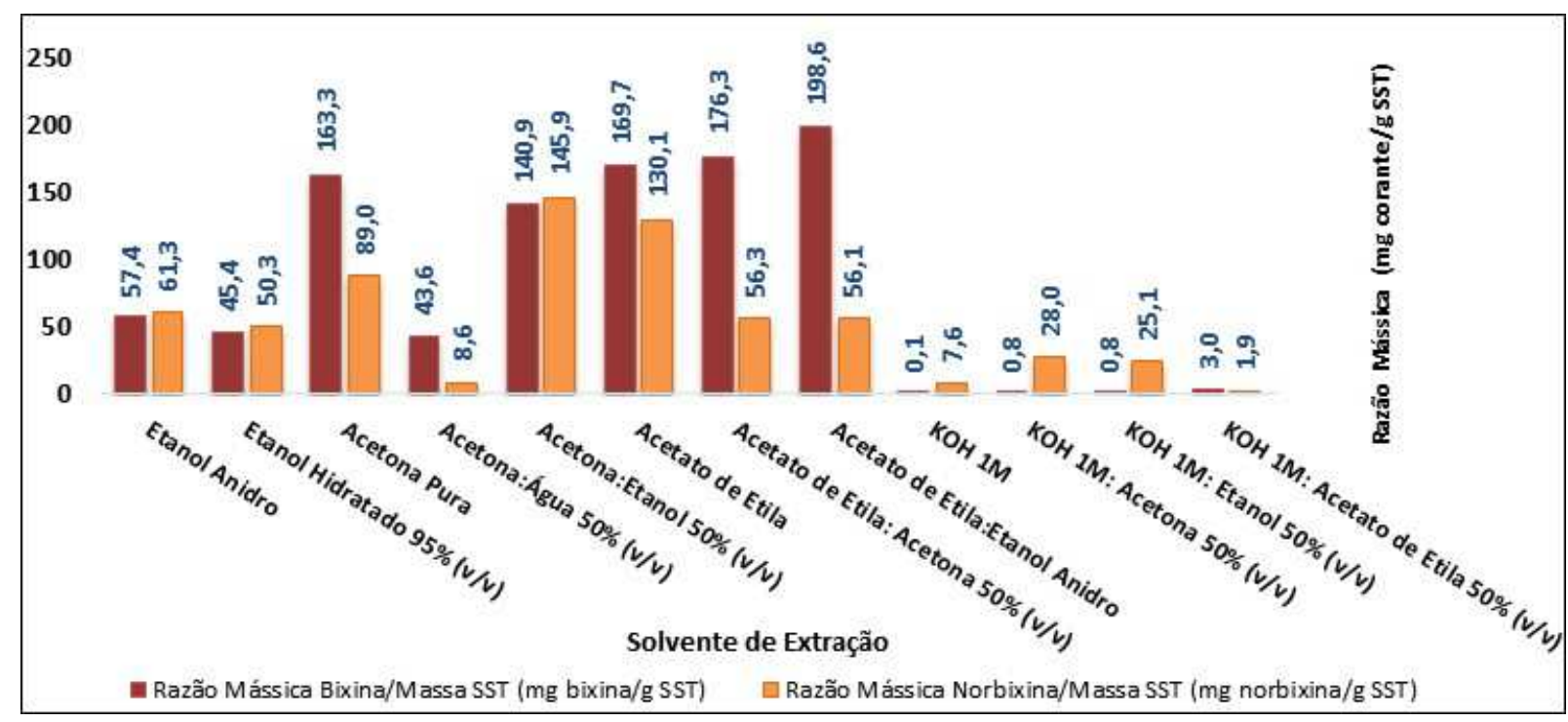

Figura 3 - Razões mássicas de bixina e norbixina para os extratos obtidos.

Estudo da influência da temperatura e da granulometria: Para aumentar a extração da bixina e norbixina do urucum, foi estudada a variação da temperatura de extração e do tamanho de partícula do sólido. Escolheram-se temperaturas que não degradassem os corantes, de acordo com os dados da literatura (SILVA, 2007). A Figura 4 apresenta os resultados obtidos de massa de corante extraído por massa total do extrato líquido.

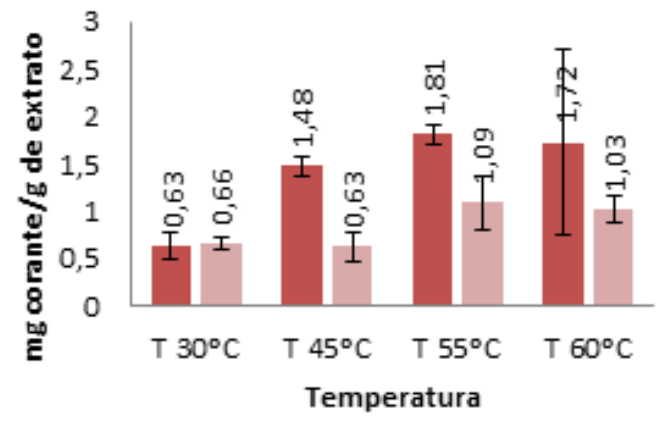

(A)

Bixina Norbixina
(B)

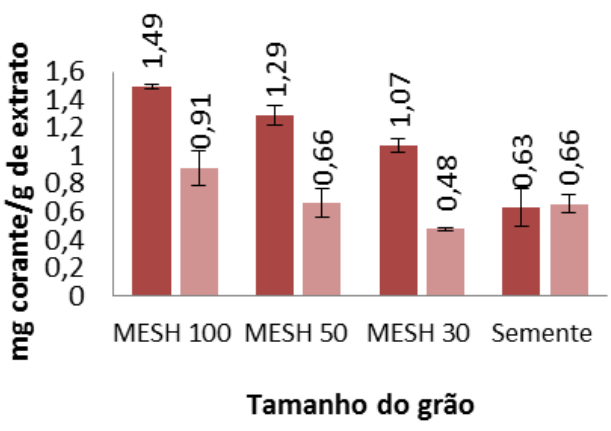

Bixina Norbixina

Figura 4 - Influência da: A) temperatura e B) granulometria na extração. 
No caso da temperatura, na maior parte dos casos a solubilidade do material aumenta com a elevação da temperatura, contudo pode-se observar um início de degradação na temperatura de $60^{\circ} \mathrm{C}$ (Figura 4). Com isso foi possível determinar a temperatura ótima em $55^{\circ} \mathrm{C}$. Quanto ao tamanho da partícula ocorreu uma melhora na transferência do soluto com a redução do diâmetro da partícula, devido à maior área superficial (Figura 4). Com isso o tamanho da partícula escolhido foi o de $100 \mathrm{MESH}$.

Estudo da influência da quantidade de sólido e do tempo de extração: Com o intuito de estudar a influência do tempo de extração e da quantidade de sólido, realizaram-se 3 ensaios em diferentes razões mássicas de sólido/solvente de 0,$125 ; 0,25$ e 0,42 ( $\mathrm{g}_{\text {urucum }} / \mathrm{g}_{\text {solvente}}$ ). Foram coletadas amostras para determinação da quantidade de bixina e norbixina extraídas em diferentes tempos, como apresentado nas Figuras 5 e 6.

Através dos resultados obtidos, apresentados na Figura 5 para a bixina e na Figura 6 para a norbixina, observa-se que o solvente é saturado num tempo curto de extração $(<20$ min), pode-se perceber que a curva de saturação possui um comportamento linear e constante, e foi possível observar a saturação do solvente quanto à semente, assim que a mesma entra em contato com a fase líquida, em todas as proporções de extração estudadas.

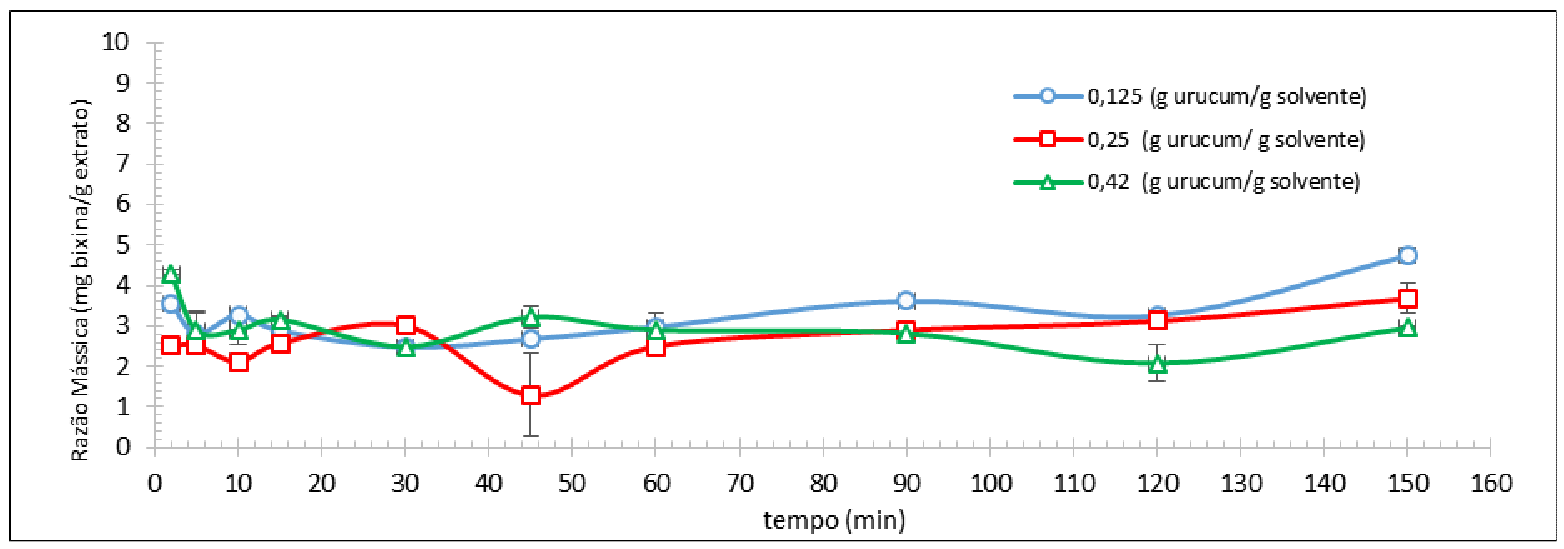

Figura 5 - Influência do tempo e da quantidade de sólido na extração de bixina.

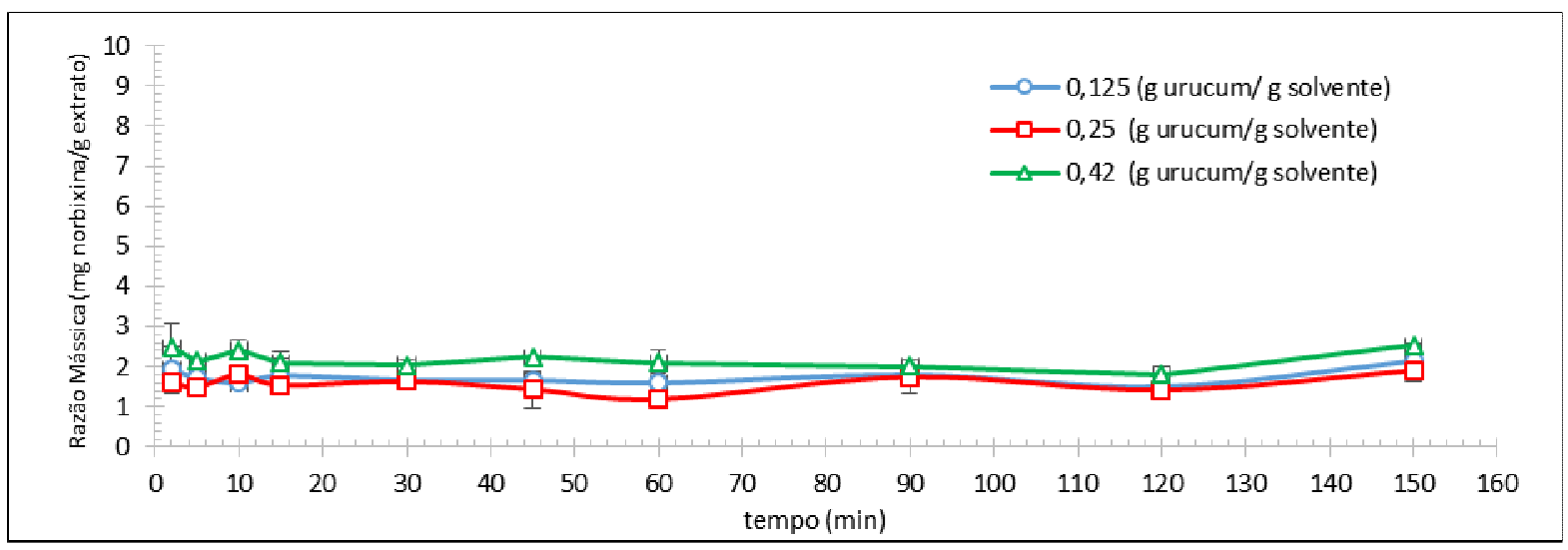

Figura 6 - Influência do tempo e da quantidade de sólido na extração de norbixina. 
As conclusões experimentais mostraram que as proporções de extração estudadas não tiveram grande influência na quantidade de corante extraído, seja ele bixina ou norbixina, demonstrando que foi possível obter bons resultados com a menor quantidade de sólidos, 0,125 (g urucum $/ \mathrm{g}$ solvente). Os dados apresentados reforçam a escolha da proporção utilizada ao longo do trabalho, uma vez que esta foi a de melhor manuseio, por não apresentar tantas partículas suspensas, e de menor custo, pela redução na quantidade de semente utilizada. A proporção de 0,25 (g urucum $/ \mathrm{g}$ solvente) operacionalmente também foi adequada, permitindo a manutenção da agitação da suspensão formada pelo sólido e pelo líquido, porém a proporção de 0,42 ( $\mathrm{g}$ urucum $/ \mathrm{g}$ solvente), por conter uma quantidade grande de sólido em relação ao solvente mostrou-se inadequada para agitação em um processo de extração em batelada. Neste caso formou-se quase uma lama, que não permitiu a homogeneização do meio pela agitação mecânica. Seria muito difícil utilizar esta proporção em um extrator industrial, principalmente utilizando mais de um estágio de extração, pois a separação do sólido particulado do extrato líquido, por decantação, seria inviável.

Avaliando-se o tempo de extração foi possível verificar que este tempo poderia ser mais curto do que o utilizado nas extrações anteriormente realizadas neste trabalho, pois a partir de 20 minutos de contato entre o sólido e o solvente de extração já ocorre a saturação do solvente. Isso garante que os resultados obtidos anteriormente representam a extração máxima nas condições utilizadas, ou seja, no equilíbrio das fases, pois foram utilizados 120 minutos em todos os experimentos.

\subsection{Aplicação do Corante Natural e Caracterização da Proteção UV}

Após o tingimento com o extrato de urucum o tecido apresentou uma cor homogênea e bem definida, sem apresentar manchas ou danos ao tecido, como pode ser visto na Figura 7. Para a análise da proteção ultravioleta foi medido o valor de radiação existente na câmara de UV com e sem tecidos e os valores obtidos podem ser observados na Tabela 4.

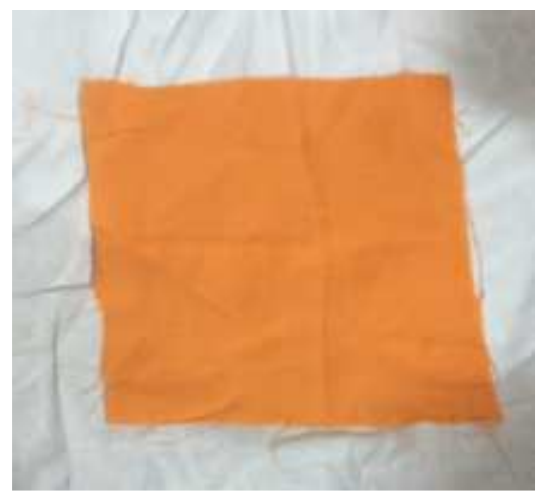

Figura 7 - Tecido Tingido

Tabela 4 - Valores obtidos na câmara de radiação.

\begin{tabular}{cc}
\hline Condição de teste & Radiação Ultravioleta $\left[\boldsymbol{\mu W} / \mathbf{c m}^{2}\right]$ \\
\hline Sem tecido & 80 \\
Tecido Algodão Puro Alvejado & 15 \\
Tecido Algodão Puro Tingido & 9 \\
\hline
\end{tabular}


Com os valores obtidos foi verificado que houve uma redução de $40 \%$ da radiação com o tecido tingido em relação ao tecido alvejado, o que demonstra a eficácia do tingimento com relação à proteção ultravioleta. A real proteção conferida pelo tecido pode ser classificada de acordo com a porcentagem de radiação absorvida pelo mesmo, seguindo a Equação 1, para a qual obteve-se o valor de UVR $88,75 \%$ de radiação absorvida, considerado um valor aceitável devido às condições experimentais em escala laboratorial, sem adição de fixadores, ou outras substâncias inseridas industrialmente. Entretanto vale ressaltar que esses resultados só são apreciáveis para a malha estudada e não permitem classificar um fator FPU, como indica a Tabela 1. As propriedades físicas de cada malha têxtil também influenciam muito na proteção que esse tecido poderá ter contra a radiação ultravioleta.

\section{CONCLUSÃO}

Através de extrações com todas as combinações estudadas dos solventes orgânicos e soluções alcalinas, o melhor solvente de extração de bixina e norbixina do urucum foi a solução de acetona:etanol $50 \%$ (v/v). Na análise dos parâmetros de extração pode-se concluir que a temperatura ideal foi de $55^{\circ} \mathrm{C}$ devido ao maior rendimento. Já no estudo do tamanho da partícula, foi observado um aumento de mais de $100 \%$ na extração em relação à semente intacta com a utilização do tamanho da partícula de $100 \mathrm{MESH}$. Na etapa de extração em batelada, foi concluído que independente das concentrações de sólidos particulados estudadas neste trabalho, o rendimento de extração foi equivalente. Além disso, devido à saturação da fase líquida, o sólido pode ser aproveitado para mais de um ciclo de extração, otimizando o aproveitamento de todos os recursos adotados, semente e solvente, até o esgotamento da semente. Foi possível verificar uma proteção ultravioleta conferida pelo corante ao algodão alvejado de cerca de $88,75 \%$ da radiação ultravioleta exposta, conforme o objetivo do trabalho.

\section{AGRADECIMENTOS}

Ao Centro Universitário FEI pelo suporte para o desenvolvimento do trabalho.

\section{REFERÊNCIAS}

ABIQUIM, 2012. História dos corantes e pigmentos. Disponível em: $<$ http://abiquim.org.br/corantes/cor_historia.asp> Acesso em: 16 mar. 2016.

BALOGH, T. S. et al. Proteção à radiação ultravioleta: recursos disponíveis na atualidade em fotoproteção. Anais Brasileiros de Dermatologia. Rio de Janeiro, v. 86, n.4, jul./ago. 2011. ISSN 0365-0596 Disponível em: <http://dx.doi.org/10.1590/S036505962011000400016>. Acesso em: 15 mar. 2016.

BARETH, A.; STROHMAR, W.; KITZELMANN, E. HPLC and spectrophotometric determination of annatto in cheese. European Food Research Technology, v. 215, n. 4, p. 359-364, 2002.

COSTA, A. S. Tingimento de celulose produzida do pseudocaule da bananeira (musa sp) com corantes naturais. 2010. 35 f. Monografia (Graduação em Engenharia Florestal) Instituto de Florestas da Universidade Federal Rural do Rio de Janeiro, Seropédica, RJ, 2010 . 
DIAS, M. Estabilidade à radiação uv em estamparia do corante natural de urucum adsorvido em argila caulim. 2010. 125 f. Dissertação (Mestrado em Engenharia Química) - Universidade Federal de Santa Catarina. Florianópolis, SC, 2010. Disponível em:<https://repositorio.ufsc.br/bitstream/handle/123456789/93707/280379.pdf?sequenc $\mathrm{e}=1$ \&isAllowed=y $>$. Acesso em: 16 mai. 2016.

GEANKOPLIS, C.J., Transport Processes and Separation Process Principles. $4^{\text {th }}$ ed., Minnesota: Prentice Hall, 2003.

HEATON, J.W.; MARANGONI, A.G. Chlorophyll degradation in processed foods and senescent plant tíssues. Trends in Foods Science \& Technology, v.7, p.8-15, 1996.

HENRY, B. S. Natural food colours. In: HENDRY, G. A. F.; HOUGHTON, J. D. Natural Food Colorants. 2 ed. Glasgow: Blackie Academic \& Professional, 1996. p. 40-79. INSTITUTO NACIONAL DE CÂNCER JOSÉ ALENCAR GOMES DA SILVA. Histórico 2016. Disponível em : $<$ http://www2.inca.gov.br/wps/wcm/connect/tiposdecancer/site/home/pele_nao_melano ma>. Acesso em 15 nov. 2016.

INMETRO: Relatório da análise em roupas com proteção UV de uso adulto e infantil. INMETRO - Instituto Nacional de Metrologia, Qualidade e Tecnologia. Rio de Janeiro. Janeiro 2016. Disponível em: $<$ http://www.inmetro.gov.br/consumidor/produtos/roupasprotecao-uv.pdf>. Acesso em: 20 nov 2016.

LANCASTER, F.E.; LAWRENCE, J.F. High-performance Liquid Chromatographic Separation of Carminic Acid, $\alpha$ - and $\beta$-norbixin, and the Determination of Carminic Acid in Foods. Journal of Chromatography A. v. 732, p. 394-398, 1996.

MATHIAS, J. Jabuticaba. Globo Rural, 2015. Disponível em: <http://revistagloborural.globo.com/GloboRural/0,6993,EEC1411763-4529-2,00.html> Acesso em 18 mai. 2016

MENDA, M. Corantes e pigmentos. Conselho Regional de Química, IV região. Química Verde. 2011. Disponível em: <http://www.crq4.org.br/quimicaviva_corantespigmentos>. Acesso em: 6 mar. 2016.

MENTER J.M; HATCH K.L. Clothing as Solar Radiation Protection. Elsner P, Hatch K, Wigger-Alberti W (eds): Textiles and the Skin:.Current Problems in Dermatology. Basel, Karger, 2003, vol 31, pp 50-63 (DOI:10.1159/000072237).

MIRJALILI, M., NAZARPOOR, K., KARIMI, L. Eco-friendly dyeing of wool using natural dye from weld as co-partner with synthetic dye. Journal of Cleaner Production. p. 1045-1051, v. 19, 2011.

PEREIRA, G. Câncer de pele. 2016. Disponível em: $<$ http://www.cancerdepele.net.br/cancer-de-pele>. Acesso em: 11 maio 2016.

PRENTICE-HERNANDEZ, C.; RUSIG, O.; CARVALHO, P. R. N. Efeito do pH na quantidade de bixina obtida em extratos alcalinos de urucum (Bixa orellana L.). Revista Brasileira de Corantes Naturais, v. 1, n. 1, p. 182-187, 1992.

SCHIOZER, A. L.; BARATA, L. E. S. Estabilidade de Corantes e Pigmentos de Origem Vegetal. Revista Fitos, v.3, n. 2, jun. 2007.

SILVA, I.P. Métodos de extração e caracterização de bixina e norbixina em sementes de urucum (Bixa orellana L.) 2007, 159 f. Dissertação (Pós graduação em Ciência e Tecnologia de Alimentos) - Universidade Federal de Viçosa. Viçosa, MG, 2007.

SILVA, P. L. R., Comportamento Tintorial do Corante Norbixato em Diferentes Concentrações Hidrogênicas em Relação à Fibra de Algodão. 1997. 94f. 
Dissertação de Mestrado (Mestrado em Química) - Universidade de São Paulo, São Paulo, SP, 1997.

SOUZA, L. F. Ação antioxidante de compostos bioativos do urucum - bixina. 2011, 86 f. Dissertação (Pós graduação em Ciência e Tecnologia de Alimentos) - Universidade Federal do Rio Grande do Sul. Porto Alegre, RS, 2011.

VERISSIMO, S. A. Extração, caracterização e aplicação do corante de urucum (Bixa Orellana L.) no tingimento de fibras naturais. 2003, 99 f. Dissertação (Programa de Pós- graduação em Engenharia Química) - Universidade Federal do Rio Grande do Norte. Natal, RN, 2013. Disponível em: $<$ http://repositorio.ufrn.br:8080/jspui/bitstream/123456789/15862/1/SilvagnerA.pdf> Acesso em 16 mai. 2016

VIANA, T.C. Corantes naturais na indústria têxtil: como combinar experiências do passado com as demandas do futuro? 2012. Disponível em: $<$ http://www.ppgd.uemg.br/wp-content/uploads/2013/10/Teresa-Campos-Viana.pdf>. Acesso em: 15 mar. 2016.

\title{
STUDY OF THE EXTRACTION OF NATURAL DYE THAT CONFERS ULTRAVIOLET PROTECTION IN NATURAL FIBER
}

\author{
A. C. LUCARINI ${ }^{1, *}$, A. S. F. Z. TABU ${ }^{1}$, F. F. R. SILVA $^{1}$, G. A. MORAES ${ }^{1}$, G. I. PIAZON ${ }^{1}$, \\ M. P. ZURAWSKI ${ }^{1}$ \\ ${ }^{1}$ FEI University, Department of Chemical Engineering \\ *E-mail: lucarini@fei.edu.br
}

\begin{abstract}
It was studied parameters that influence the solid-liquid extraction of natural dye from annatto and the ultraviolet protection $(U V)$ conferred by its application in a natural fiber. Annato is one of the natural dyes most used worldwide and its main pigment is the carotenoid bixin, which is converted by alkaline hydrolysis into norbixin. Different organic solvents and alkaline solutions were studied for extraction: acetone, ethyl acetate, $\mathrm{KOH}$ in solution and ethanol. It was analyzed the effect of the parameters: temperature, solid particle size, extraction time and solid/solvent mass ratio. The results obtained revealed that an ideal extraction was verified using ethanol:acetone $50 \%(\mathrm{v} / \mathrm{v}), 55^{\circ} \mathrm{C}$ and particle size of 100 MESH. It was observed that the solvent saturated in 20 minutes of extraction, meaning that the solid can be used for more than one extraction cycle. The dye conferred an ultraviolet protection in bleached cotton of about $89 \%$ of the absorbed ultraviolet radiation.
\end{abstract}

KEYWORDS: Natural Dye; Extraction; UV Protection; Bixin; Norbixin. 